\title{
Gender equality management in modern company management in era of globalization
}

\author{
Viera Sukalova ${ }^{1, *}$, and Pavel Ceniga ${ }^{1}$ \\ ${ }^{1}$ University of Zilina, Faculty of Operation and Economics of Transport and Communications, \\ Department of Economics, Univerzitna 1, 01026 Zilina, Slovakia
}

\begin{abstract}
.
Research background: Today's dynamic times in era of globalization bring change to all areas of business; there is increasing pressure to increase the competitiveness of companies and thus increase the requirements for management. Despite current trends, emancipation and globalization, the issue of gender equality and gender policy is still relevant and needs to be addressed. New management disciplines include diversity management. It focuses on the different social and cultural identities of employees and also on eliminating discrimination and inequality in the organization. Diversity management has later developed into a relatively separate discipline - gender relations management. Label recognition of the organization as "gender-integrated" means that organizational culture and processes are based on the recognition and promotion of gender equality. Gender equality is associated with the concept of equal opportunities at work and actual legislation in the field of labour protection.

Purpose of the article: The aim of the paper is based on modern management trends and the legislative framework for gender equality as well as anti-discrimination management principles to analyse the current situation on the example of a case study from the requirements of a gender integrated organization and to propose systemic measures to address issues for business practice.

Methods: The method of analysis, synthesis, deduction, interview and questionnaire was used in the research. A survey was performed in 2019 on the examle of case study in big sized company in the field of machinery industry.

Findings \& Value added: Adherence to gender equality policy can be a competitive advantage for the entrepreneur. This initiative is becoming a motivating factor for entrepreneurs to launch measures that would lead to introduction and strengthening of gender equality.
\end{abstract}

Keywords: diversity management; discrimination; gender equality; legislation, labour protection

JEL Classification: J24; J28

* Corresponding author: viera.sukalova@fpedas.uniza.sk 


\section{Introduction}

At present, the issue of disadvantage of women compared to men is increasingly being discussed. Women in men's work positions break down stereotypes of the current functioning of the current world of work. The issue of gender equality and gender policy is now increasingly relevant and needs to be addressed. Society is aware of how the gender equality system should work, but it is not always able to successfully apply it in practice. Many problems in gender equality are conditioned by the system in which we grow up, our learned attitudes, given stereotypes and the perception of circumstances with only one point of view. In the age of globalization and the open world, this perspective needs to be broadened and things looked at differently. The essence of Diversity Management is the integration of the principle and the process of diversity into everyday life managerial practices and the learning process within the company. Managers want results; mostly they are not interested in aesthetically pleasing general theories. In order to achieve their goal and gain advantage over competitors need to understand which of the possible forms of diversity they can provide strategic advantage, or limit their ability to achieve their goals. [1] All factors of a company's competitiveness depend on the quality, performance, productivity and other capabilities of human activities. It is a logically and strategically thought-out approach to managing the company's employees. The main task of human resources is to find a match between the number and structure of jobs and job seekers, provided that the jobs comply not only with the legislation but also with the abilities of the employee himself. Understanding the relationship between employee motivation and performance is an important step to an organization's success. Through managers, it is possible to influence the abilities, motivation or performance of employees. The correct performance of the personnel function is conditioned by the knowledge of personnel activities without distinction, disadvantage or advantage of the employee. The aim of our paper is to analyse the approach and perception in the management of gender relations in the case study and to define recommendations for the practice of companies.

\section{Methodology}

The aim of our research was to analyse the perception of gender management by middle managers of the company. The methodology of research includes literature review; desk review (to analyse secondary data, to research the latest theoretical and practical developments in management). Primary data were collected by questionnaire and semi structured interview. The method of analysis, synthesis, deduction, interview and questionnaire was used in the research. The selected company for the example of case study operated in the field of machinery industry; it was a big-sized company and with potential to grow in the future. The survey was conducted using a quantitative method, in the form of a questionnaire survey, furthered by expert interviews with human resources management. The target group was represented by the company's middle managers. Twenty four middle managers of the company participated in the survey. The survey was carried out from February to April 2019. The electronic questionnaire consisted of thirty four questions, with verbal scale (Likert scale), as well as open questions focused on the gender segregation and antidiscrimination gender management principles perception of middle management in praxis of the company. The questionnaire was sent to twenty nine middle managers and a total of twenty five valid questionnaires returned, which represented a return of $86,2 \%$. The study focused on selected aspects of company management from the gender management point of view. The aim of our research was to analyse the perception of gender management by middle managers of the company. 


\section{Results}

As gender management is a relatively new issue in the practice of management, it is necessary to explain the basic concepts before introduction of gender management perception results.

\subsection{Basic terms}

The word diversity means diversity. We understand the phrase diversity management as management, diversity management. Hubbard (2004) defined diversity management as the process of planning, organizing, directing and supporting mixed teams that have the potential for high performance. [2] Gender equality is a social situation in which all beings have the right to develop and decide freely without restriction. It is a state of fair treatment for women and men. This means that not only will their social status be the same in all spheres, but also their perception, respect or evaluation will be full-fledged. Society uses this term mainly because of the effort to equalize the social status of men and women. In most cases, the path of disadvantage is limited to women. The main goal of gender equality is to create a decent space that respects every woman as well as every man. Job satisfaction is a positive or pleasant emotional state resulting from a subjective perception of an individual's work experience. Public sector workers' job satisfaction is essential because it affects public services. It can lead to a positive and desirable organizational behaviour and outcomes. $[3,4,5]$ Gender roles represent a complex of social behaviour that is required in a certain social position and is understood as standard. It represents, for example, the role of a woman, a man, a child and what behaviour is expected of them. The company automatically perceives his or her role based on the social position. Gender stereotypes assess the abilities and characteristics of women and men, beliefs in activities and characteristics that are appropriate only for women and specifically only for men. So they create images of masculinity and femininity. They talk about what men and women should be, forgetting the uniqueness of each person. Stereotypes are becoming a problem because modern society requires that they be applied to everyone. Despite the implementation of a number of laws or the organization of various projects on the topic of gender equality, we can confirm that gender stereotypes still persist. They are visible mainly in areas such as women's study or career decisions or the fact of women's representation in political life. However, stereotypes do not always play only a negative role. In some life situations, they make it easier for us to orient ourselves, even if they lead to superficiality. In conclusion, we can evaluate that the negative stereotypes include mainly those that keep one sex (more often women) in a subordinate position. [6] Gender equality is often associated with the concept of equal opportunities. It is not understood as equality with the establishment of living conditions, but as the application of decisions without being limited by any established norms (gender stereotypes) or prejudices. It can be understood as a very broad concept of equality, from equality between genders, but also equality according to age, education, health status, nationality, religion, etc. Gender equality is implemented in EU and Slovak law. However, society lacks the implementation of this concept into real everyday life, i.e. into practice. The adoption of the principle of non-discrimination has thus taken on a constitutional value. The high growth of increasing multinational companies with an internationalized organizational culture and advanced policies to promote diversity has contributed to the transformation of the business environment in Slovakia and to raising awareness of all types of discrimination, including the introduction of gender equality in companies. [7] According to several international sources, women's wages are still significantly lower than men's. Every year, this information is measured by the Gender Equality Index as a tool for measuring the progress of gender equality. It was developed by 
the European Institute for Gender Equality (EIGD). EIGE discusses that there are many issues behind the gender gap, such as employment rates, part-time work, unpaid care and parental responsibilities. The index has six main areas - work, money, knowledge, time, power and health - and two secondary areas: violence against women and overlapping inequalities. It highlights areas where improvement and the design of more effective measures are needed. The index also points to the diverse reality that different group of women and men face. A special part of this index is the link between private and public life together with gender equality. [8] Women's employment and engagement are now increasing more and more. Since 2000, women have filled three quarters of the millions of new jobs created across the EU. Based on general statistics, we can say that more girls than boys currently do in school and make up $59 \%$ of EU university graduates. The article by Delgado and Guller (2017) seeks to emphasize the fact that 21 st century women can succeed in all positions, including managerial (managerial - middle and top management), although it may be more difficult because the world of management - is still dominant for men. Even on the basis of this information, it is a fact that women currently earn $17 \%$ less than men and own fewer senior positions. [9] From the analysis of Mitková (2018), the highest difference in the remuneration of women and men was found in the group of occupations "financial and insurance activities. [10]. this is also linked to the fact that gender differences in the labour market have been affected by employment dynamics. Gender equality is part of the anti-discrimination principles in the work environment, which are regulated by European and national legislation.

\subsection{Legislative aspects of gender equality in the Slovak Republic}

The most important document of the Slovak Republic, the Constitution, guarantees equality of citizens in general, i.e. also on the basis of gender (Article 12, Chapter 2, Fundamental Rights and Freedoms). The Slovak Republic, as a member state of the United Nations, is governed by UN documents on equality issues. The basic ones include: UN Charter (valid from 26.06.1945), Universal Declaration of Human Rights (10.12.1948), and UN Declaration on the Elimination of Discrimination against Women (7.11.1967), International Labour Organization-ILO Conventions, and UN Declaration on the Elimination of Violence against Women. Anti-discrimination law is part of the legislation of the Slovak Republic. The carrier and a basic regulation governing the principle of equal treatment in the exercise of such powers dependent work is the Constitution of the Slovak Republic. In the area of industrial relations is key legislation regulating the area the Labour Code, the AntiDiscrimination Act and other regulations regulate similar employment relationship The Labour Code guarantees women and men the right to equal treatment if: these are access to employment, remuneration and workflow, vocational training and working conditions. The right to equal treatment shall apply to employees, as well as jobseekers. Discrimination of employees on grounds of labour law is prohibited in industrial relations gender, marital and family status, sexual orientation, race, skin colour, language, age, adverse medical condition or disability, genetic characteristics, faith, religion, political or other thinking, trade union activity, national or social origin, belonging to a nationality or ethnic group, property, gender, or other status, or because of a crime or otherwise anti-social activities. Article 6 of the Labour Code of the Slovak Republic establishes fundamental rights for women and men with regard to the right to equal treatment as regards access to employment, remuneration and promotion, vocational training and working conditions. Pregnant women, mothers up to the end of the ninth month after childbirth and breastfeeding women are provided with working conditions that protect their biological condition in connection with pregnancy, childbirth, childcare after childbirth and their special relationship with the child after childbirth. Women and men are provided with 
working conditions that enable them to perform a social function in the upbringing and care of children. In 2011, on the basis of Resolution 158/2011, the Council of the Government of the Slovak Republic for Human Rights, National Minorities and Gender Equality was established. This institution is one of the three advisory committees of the Government of the Slovak Republic. It is a permanent professional body of the Council of the Slovak Republic for areas related to gender equality and for monitoring the implementation of the Convention on the Elimination of All Forms of Discrimination against Women and other human rights conventions and the achievement of set EU goals. A number of nongovernmental organizations have been established in the Slovak Republic on the issue of women's rights and gender equality. The best known are: Active women; Alliance of Women of Slovakia; Club of Feminist Philosophers; National Centre for Equal Opportunities; Citizen, democracy, responsibility; Nutrition, Slovak Women's Association and others. The National Labour Inspectorate and labour inspectorates are state administration bodies. Their function is to supervise compliance with labour law regulations, including the application of gender equality, special working conditions for women and men, or adequate and legally regulated pay.

\subsection{Management from the aspect of diversity in era of globalization}

Globalization is changing the face of the world. But doing business in the international arena is not without its pitfalls. One area that has received attention is the potential for misunderstandings that can occur when two companies that are culturally different do business with one another. A problem which may exacerbate cultural conflict in the international arenas is when the policy of the corporate parent and the mores of its management team are at odds with the values of employees in the host country. [11] Gender equality is a major issue in modern management, both public and private. There are two basic principles that complement each other: the first consist of social justice, which leads to providing women with the same opportunities as men in terms of access to jobs, including senior management, subsequently implementing actions of positive discrimination to solve disadvantages of the past. The second principle is the growing evidence in academic and business literature that when teams in general and management boards in particular, are more diverse, also in terms of gender, firms experiment a significant business enhancement. Both realities can play the role of market signalling by the firms, in order to capture the attention of a growing crowd of more responsible investors, commercial allies, potential candidates for key job positions, etc. [12] Companies are under increasing pressure from the environment, regulators, interest groups and public opinion to be increasingly transparent and more ethical. [13] Heterogeneity in team member characteristics has been and continues to be one of the central questions in research on management teams. [14] According to the research work of the team of authors Srinidhi, B. et al. we know and it has been proven that companies with "female" directors perform better than companies with "male" directors. Their work points out how effective women can manage even without a majority share in management positions. Empirically, they point out that independent directors are much more efficient than directors. [15] Other research shows that Female managers were more convinced to the benefits of Corporate social responsibility practices than their male counter-parts. [16] A fuller understanding of diversity and inclusion requires a focus also on senior leaders' roles in diversity leadership. Hierarchy of company has also great impact on the company prosperity; informal hierarchies are a common and important feature of many groups, yet we know little about the antecedent conditions that determine the strength of such hierarchy. [17] Modern sexist beliefs are currently emerging as one of the most important barriers to achieving gender equality in managerial positions in organizations. [18] The other study found that the main 
barriers in women's career enhancement were work-life imbalance, subordinates' perceptions regarding women leaders, social networking, and personal factors. The factors which motivated women leaders to advance in their career path were continuous family and mentor support, changing mind-set of employers, and potential leadership competency of women leaders. [19] It is also very important to notice the relevance of the automat ability of male and female jobs, the number of women and men in occupations with low and high risk of automation. [20] Beth Turnbull et al. (2020) explores and integrates existing theories of gender hegemony into a multidimensional, multilevel, relational and intersectional perspective for exploring internal and external relations within and between hierarchical configurations of femininities and masculinities. [21] Gender management and diversity policy at work has an important impact on the well-being at work. It is important for public as well as private organisations to pay attention to the cost of occupational stress-related illness of line managers and to design the working context and workplace support interventions built on empirically based knowledge on managers' job situation, gender perspective and the focus on wellbeing at work. [22] The manager should assume that each person is unique, unique, unique in nature and his or her human rights are the same as anyone else's. "My freedom ends there. Where the freedom of the other begins, "the statement of the philosopher Jean Jacques Rousseau was the impetus for the establishment of a free democratic system, such as we live in today. Following on from this idea, people are still classified into gender, and we know that in the past and in the present, these sexes were not equal and are not, even though we are trying to do so. This problem was a clear impetus for the creation of such a system of functioning of the company, where the manager does not have to be honest and fair to everyone. It can favour or disadvantage someone not only on the basis of another gender. The role of the manager is to be key factor to achieving business advantage in all areas. Diversity management is one of the key factors determining the success of managerial activities in the current changing environment. [23] The competencies that managers must acquire, generally, the managers of the HRM departments and other managers working in a global environment should have a global mind-set, international experience, strong technical and strategic skills. It is necessary to focused on the intercultural and interpersonal knowledge; the ability to adopt other cultures, global leadership and leadership skills for human resource management throughout the organization and its individual branches; mastering change management and diversity management. It was also learnt that leadership is one of the leading factors in bringing affirmative change in organizations. [24] Bridging gender gaps in the workplace is a crucial component of inclusive and sustainable growth. [25]

\subsection{Gender management perception}

We examined issues related to gender management on the example of big sized international company in the field of machinery industry using the method of interview and questionnaire. We introduce selected aspects of the search. The labour market is generally structured by gender. Women and men are concentrated in specific departments and positions. Women usually hold lower positions while men are in higher positions. This specific concentration is referred to as "gender segregation". We divide it into horizontal (representation in different job positions) and vertical (concentration at different levels of management). Gender segregation of occupations also has a positive aspect for women and a negative aspect for men. Regarding gender representation in management positions, there are 3 women in senior management in the surveyed company. The percentage of managers is only $4.1 \%$. In administrative positions, we observed women mainly in the finance and administration department. Oher staff is largely represented mainly by men. We focused also on the double life of women. Women's working careers are very closely linked to 
personal family life. It should be emphasized that the company does not follow the fact of being hired / married, having children or not when hiring an employee. Women as mothers have a number of special maternity rights under the law. The surveyed company rewards employees in a table, according to the difficulty of the position, the associated responsibility and the number of hours worked, regardless of gender. In this way we can say that the chosen company does not disadvantage women in remuneration. Of course, their remuneration depends on the individual functions. We know from internal sources that the company offers the possibility of earning overtime, as long as the employee does not take overtime work as compensatory leave. Just from the information that women work in the company less than men, it will be clear that the number of hours for women will be much lower than for men. Another factor that influences these numbers is the fact that women are mothers who mainly take care of children, run a family or even mothers as caregivers for their elderly parents. The man, as the breadwinner of the family, stays longer at work, earns more, works overtime to ensure the family's finances. Antidiscrimination principles are also in the corporate culture through the Code of Ethics. Corporate culture represents a complex of values, attitudes, norms, or unwritten rules of conduct and functioning of a company. Another method we used to ask for information was a questionnaire survey. Despite all administrative measures, principles, updating the company's operations in accordance with applicable laws, standards and respecting the rights of the company's employees, especially by applying the principle of gender equality, it is confirmed that the proportion of working men and women is not even the same. In practice, therefore, the number of employees is significantly higher than the number of female employees. The aim of this section was to find out the reason why this is the case, to focus on the individual differences of employees, to find differences between them that may be the reason for the problem. Most of managers in company are men; of the given number only $23 \%$ are women. The selected sample had a much lower proportion of women than men. This can be seen as a coincidence or indirect evidence of discrimination in women's employment. In the following questions, we focused on the individual life facts of employees, how they differ from each other as individuals, to find out the main reason for the difference. The age group from 36 to 45 years had the largest representation. In terms of percentage, it accounted for 53.3\%. It was followed by a group of 26 to 35 year old employees, which represents $46.7 \%$. From the results we can say that a larger group consists of employees at a mature age, due to their experience, previous experience and expertise. We also found out in the questionnaire that it is mainly employees who have gone through several positions. Their dexterity guaranteed them career growth. Therefore, it is not surprising that a group of employees under the age of 25 has no representation in the given positions. While they are occupied in lower positions, over time they can advance higher. Employees over the age of 56 are also not represented. We can estimate several factors as a reason. These include, for example, the modernization and automation of the company, where it is more difficult for older employees to adapt. The company pays attention to a diverse age structure, so that the teams are age-diverse, while adhering to the rule of age average in a team of about 35-40 years. All respondents (100\%) were of Slovak nationality. The question is very important given the fact that the company belongs to a global cooperation, so the foreign representation did not have to be a surprise. As a result, we can confirm the above-mentioned facts that the education of respondents, their skills led them to current positions. Another part of the questionnaire was devoted to parenting issues; the main aim was to find out whether the employer does not discriminate mainly on the grounds of maternity. Based on these answers, we can confirm that the company does not discriminate on the basis of parenthood, as in the sample we see that women in important positions in an international company are not only perceived as careerists, but also as mothers. We see from the recorded answers the fact that $33.3 \%$ did not increase 
their career but performed several positions. The possible reason is their experience, or their broad perspective and the effort to learn something completely different. On the other hand, up to $66.7 \%$ respondents increased their careers. An important fact is the number of years worked in the selected company. Those employees who have been working for the company for 15 years since its establishment are aged 36-45, with one woman and two men redistributed, and have held several positions in which they have also increased their careers.

\section{Discussion}

Based on the results of the analysis, it can be stated that the company in principle adheres to the principles of management in the promotion of gender equality. There is a fair recruitment of new people in the company. The situation is influenced by job seekers and conditioned by the technical focus of the company, which affects the greater interest in work on the part of men. A fair division of labour and work tasks between women and men is conditioned by the segregation of employees. The company focuses more on the diverse structure of work teams in terms of age rather than gender, as the situation is conditioned by the industry and the influx of female employees is smaller. The company creates equal opportunities for employment and career advancement for all employees equally, regardless of gender; wages are governed by tables and wage tariffs, differences are only on the basis of vertical redistribution of posts. The company creates working conditions that ensure equal opportunities for men and women. Prevention of discrimination is regulated in the code of ethics; the company provides without distinction of opportunities in further education and deepening of qualifications. We see reserves mainly in the reconciliation of work and private life; the company is dealing with the issue, but there are still things that can be improved or supplemented. We can recommend better dialogue and communication in the company. Further research will be focused on the employee perception of the gender management, because we can supposed, that there is a difference between the perception of gender principles of employer and employees.

\section{Conclusion}

With the help of a personal interview and a questionnaire analysis, we found out that there are unequally represented areas in the company. In the company's practice, it is still necessary to work on improving gender representation, for example by implementing relevant solutions. The introduction of measures to reconcile work and family life would increase the attractiveness of work not only for women - mothers, but also for men fathers. Although the company produces in the technical engineering sphere, where there is a greater representation of men, it is necessary for us to break down stereotypes such as that only men are interested in technology. Women are those who can make the company much more efficient, prosperous and advanced. It is known that it is said that the same thing always requires a masculine but also a female opinion and perspective. Improving the management of gender relations is also a recommendation for other large companies in the Slovak Republic, in which we perceive a similar problem of gender representation. Of course, first and foremost, it is important that businesses do not directly or indirectly discriminate against one sex and make a difference based on what nature has given us.

This paper is an output of the Science Project No. 4/PEDAS/2019 Sustainable Human Resources Management in Era of Globalization and VEGA No. 1/0619/20 VEGA No. 1/0619/20 Fundamental research of quantitative and qualitative determinants of innovation potential and innovation 
performance of a company in relation to increasing its competitiveness; VEGA no. 1/0064/20. Behaviorism in a socially responsible communication strategy of enterprises

\section{References}

1. Keil, M., Amershi, B., Holmes, A., Jablonski, H., Lüthi, E., Matoba, K., Plett, A., von Unruh, K. (2007). Diversity Management - Training manual. International Society for Diversity Management.

2. Mussa, H., Debnarova, L., Musova, Z., Kristofik, P. (2017). Gender equality and corporate governance in Slovakia. E\&M Ekonomie a Management, 20(1), 98-110.

3. Locke, E.A. (1976). The Nature and Causes of Job Satisfaction. Handbook of Industrial and Organizational Psychology, 1, 1297-1349.

4. Mundia, L. (2019). Satisfaction with work-related achievements in Brunei public and private sector employees. Cogent Business \& Management, 6(1), 1664191.

5. Pecino, V., Mañas, M. A., Díaz-Fúnez, P. A., Aguilar-Parra, J. M., Padilla-Góngora, D., López-Liria, R. (2019). Organisational Climate, Role Stress, and Public Employees' Job Satisfaction. International Journal of Environmental Research and Public Health, 16(10), 1792.

6. Stiegler, B., Michalitsch, G. (2009). Spravodlivost'v rodových vzt'ahoch. Bratislava: Zaujímavé združenie žien ASPEKT.

7. Delaneuville, F., Mitková, L. (2018). Discrimination of women in the Slovak labor market: Legal and sociological analyses. In K. S. Soliman (Ed.), Vision 2020: Sustainable Economic Development and Application of Innovation Management from Regional expansion to Global Growth: Proceedings of the 32nd International Business Information Management Association Conference IBIMA 2018 (pp. 1645-1652), Seville, Spain: IBIMA.

8. Mejia-Dorantes, L. (2019). Discussing measures to reduce the gender gap in transport companies: A qualitative approach. Research in Transportation Business and Management, 31, 100416.

9. Delgadová, E., Gullerová, M. (2017). Female managers and their characteristics in the Treňín region, Slovakia. Problems and Perspectives in Management, 15(2), 549-556.

10. Mitjová, L. (2018). Occupational segregation and gender pay gap in Slovakia. In K. S. Soliman (Ed.), Innovation Management and Education Excellence through Vision 2020: Proceedings of the 31st International Business Information Management Association Conference IBIMA 2018 (pp. 5023-5030). Milan, Italy: IBIMA.

11. Markert, J. (2009). Social Eclipses and Reversion to Type: Sexual Issues Confronting Postmodern Men and Women Working in Strongly Patriarchal Societies. Theory in action, 2(1), 86-109.

12. Srivastava, R. K., McInish, T. H., Wood, R. A., Capraro, A. J. (1997). Part IV: How do reputations affect corporate performance? The value of corporate reputation: Evidence from the equity markets. Corporate Reputation Review, 1(1), 61-68.

13. Baez, A. B., Baez-Garcia, A. J., Flores-Munoz, F., Gutierrez-Barroso, J. (2018). Gender diversity, corporate governance and firm behavior: The challenge of emotional management. European research on management and business economics, 24(3), 121-129.

14. Bunderson, J. S., Van der Vegt, G. S. (2018). Diversity and inequality in management teams: A review and integration of research on vertical and horizontal member 
differences. Annual Review of Organizational Psychology and Organizational Behavior, 5, 47-73.

15. Srinidhi, B. (2020). How do female directors improve board governance? A mechanism based on norm changes. Journal of Contemporary Accounting and Economics, 16(1), 100181.

16. Martins, L. L. (2020). Strategic Diversity Leadership: The Role of Senior Leaders in Delivering the Diversity Dividend. Journal of Management, 46(7), 1191-1204.

17. Oedzes, J. J., Van der Vegt, G. S., Rink, F. A., Walter, F. (2019). On the origins of informal hierarchy: The interactive role of formal leadership and task complexity. Journal of Organizational Behavior, 40(3), 311-324.

18. Delgado-Iglesias, A. J., Ortiz-Lopez, M., Monteoliva-Sanchez, A., Aguilar-Luzon, M. D., Calvo-Salguero, A. (2019). Moderating Role of the Experience of having had a Female Boss in Relationship between Neosexism and Unfavorable Attitudes toward Female Leaders. Journal of psychology, 153(4), 436-461.

19. Maheshwari, G., Nayak, R. (2020). Women leadership in Vietnamese higher education institutions: An exploratory study on barriers and enablers for career enhancement. Educational Management Administartion and Leadership, 41(1), 79-94.

20. Kral, P., Janoskova, K., Podhorska I., Pera A., Neguriță, O. (2019). The Automatability of Male and Female Jobs: Technological Unemployment, Skill Shift, and Precarious Work. Journal of Research in Gender Studies, 9(1), 146-152.

21. Turnbull, B., Graham, M., Taket, A. (2020). Hierarchical Femininities and Masculinities in Australia Based on Parenting and Employment: A Multidimensional, Multilevel, Relational and Intersectional Perspective. Journal of Research in Gender Studies, 10(2), 9-62.

22. Jonsdottir, I. J., Rafnsdottir, G. L., Ólafsdóttir, T. (2020). Job strain, gender and wellbeing at work: a case study of public sector line managers. International Journal of Workplace Health Management, 13(4), 445-460.

23. Lu, J., Ren, L., Zhang, C., Wang, C., Petkeviciute, N., Streimikis, J. (2020). Gender difference in corporate social responsibility implementation in Lithuanian SMEs. Oeconomia Copernicana, 11(3), 549-569.

24. Mansaray, H. E. (2019). The Role of Leadership Style in Organisational Change Management: A Literature Review. Journal of Human Resources Management, 7(1), 18-31.

25. Seung. H. Y. and Byung Y. J. (2020) Gender Differences in Wage, Social Support, and Job Satisfaction of Public Sector Employees. Sustainability, 12(20), 8514. 